\title{
HIGH-RESOLUTION RESIDUAL TERRAIN MODEL AND TERRAIN CORRECTIONS FOR GRAVITY FIELD MODELLING AND GEOID COMPUTATION IN NIGER REPUBLIC
}

\author{
Salissou IBRAHIM YAHAYA ${ }^{1^{*}}$, Driss EL AZZAB ${ }^{2}$ \\ 1, 2 Geo-resources and Environment Laboratory, Faculty of Sciences and Techniques, \\ Sidi Mohamed Ben Abdallah University, Mail box: 2202, Imouzzer Road, Fez, Morocco \\ ${ }^{1}$ Department of Surveying, Institute of Technology (IUT), University of Zinder, Mail box: 656, Zinder, Niger
}

Received 11 July 2018; accepted 20 September 2018

\begin{abstract}
In this study, we computed and presented grid maps of high-resolution terrain corrections and residual terrain model (RTM) as short-wavelengths of the gravity field and the geoid in Niger. We constructed RTM elevations from mean elevation surfaces corresponding to $\sim 100 \mathrm{~km}$ and $\sim 9 \mathrm{~km}$ of spatial scales and 3 arc-seconds SRTM data. The computations are performed at gravity stations and 1.5 arc-minute regular grid, out to 10 and $200 \mathrm{~km}$ for inner and outer zones respectively with the standard density of $2670 \mathrm{~kg} / \mathrm{m}^{-3}$. The study area is characterized by low values of terrain effects. The indirect effects are lower than $10 \mathrm{~cm}$ for $\sim 9 \mathrm{~km}$ and reach $1.8 \mathrm{~m}$ for $\sim 100 \mathrm{~km}$. In Niger, $98.44 \%$ of indirect effects are lower than $1 \mathrm{~cm}$ and $98.2 \%$ of direct effects are lower than 5 mgal for $\sim 9 \mathrm{~km}$. For $\sim 100 \mathrm{~km}, 85.87 \%$ of indirect effects are lower than $10 \mathrm{~cm}$ and $89.77 \%$ of direct effects are lower than $5 \mathrm{mgal}$, and $98.77 \%$ of terrain corrections are lower than $1 \mathrm{mgal}$. We found out that height discrepancies between gravity stations and SRTM influences the precision of terrain effects. The results are valuable for applications in geodesy and geophysics that require accurate interpretations.
\end{abstract}

Keywords: gravity field, geoid, short-wavelengths, Residual Terrain Model, terrain corrections, SRTM, Niger.

\section{Introduction}

The gravity reductions serve as tool for geoid determination in geodesy, interpolation and/or extrapolation of the gravity and the investigation of the Earth's crust in geophysics and geology (Heiskanen \& Moritz, 1967). There are numerous gravity reduction methods: Bouguer, Isostatic, Rudzki, Helmert and Residual Terrain Model (RTM) (Tziavos \& Sideris, 2013). Officially, the Republic of Niger does not yet have a gravimetric geoid model. The gravity survey date from the 1960s, only simple Bouguer anomaly maps had been published (Rechenmann, 1969), the gravimetric terrain corrections are not available for the country. Nowadays, the high-resolution Global Geopotential Models (GGM), like EGM2008 (Pavlis, Holmes, Kenyon, \& Factor, 2012), are a good alternative for modelling the gravity field and geoid, but they are subject to omission error comprising high-frequency gravity field signals that cannot be represented by a truncated spherical harmonic series expansion (Torge, 2001).
In the Remove-Compute-Restore (RCR) method for geoid/quasigeoid determination, the short- and longwavelengths of the gravity signal are removed, making the gravity anomalies as small as possible, prior to gridding process and integration (Remove step). The residual gravity anomalies are used in Stokes'/Molodensky's integral to obtain the residual geoid/quasigeoid (compute step). The resulting geoid/quasigeoid is obtained by restoring the removed signals to the residual one (Restore step) (Heiskanen \& Moritz, 1967).

The contribution of long-wavelengths to the gravity anomaly and geoid/quasigeoid is computed from GGM. The short-wavelengths are computed from digital elevation model (DEM), because the Earth's topography is the main source of high-frequency gravity field (Forsberg, 1984). The achieved accuracy of geoid/quasigeoid depends on the three contributions. Studies are carried out around the world to select the GGM that better describe the long-wavelength before its use in geoid computation and gravity field modelling. Ismail (2016) reported that

*Corresponding author. E-mail: salissou.ibrahimyahaya@usmba.ac.ma 
the achieved accuracy of gravimetric geoid during the last decades is related to the accuracy of topographic data.

The Residual Terrain Model (RTM) was introduced by Forsberg (1984) for RCR approaches, in this technique, topographic irregularities relative to a smooth mean elevation surface, with resolution comparable to that of the used GGM, are computationally removed. The magnitude of RTM effects decreases as the resolution of the reference surface increases (Forsberg, 1984). The mean elevation surfaces are determined by topographic spherical harmonic expansions or low-pass filtering of global digital elevation model (GDEM). RTM leads to the quasigeoid that is further converted to the geoid. The RTM has the advantage of not considering twice the effect of long wavelengths in geoid computation. The RTM technique is capable of modelling major parts of high-resolution GGM omission error and can improve geoid determination in mountainous area (Hirt, Featherstone, \& Marti, 2010).

The Shuttle Radar Topography Mission (SRTM) GDEMs (Jarvis, Reuter, Nelson, \& Guevara, 2008; NASAJPL, 2013) showed the best vertical accuracy in Niger and surrounding areas with precise ground control points. Their comparison with the gravity database elevations showed important height discrepancies (Ibrahim Yahaya \& El Azzab, 2018). Both elevation sources are subject to errors of vertical and/or horizontal positioning, it is reported in several studies that SRTM GDEMs did not require horizontal shift (Varga \& Bašić, 2015). Since GDEMs are used in RTM computations, this may yield errors in terrain effect at gravity stations.

This study focuses on modelling the short-wavelengths of the gravity field and hence the geoid through the residual terrain model approach over Niger. We construct RTM elevation from SRTM GDEM (Jarvis et al., 2008).
We investigate on the parameters influencing the accuracy of RTM effects and terrain corrections to seek a compromise between computation time, computer limitations and accuracy. We compare the mean elevations surfaces computed from low-pass filtering of GDEM and topographic spherical harmonic model. We analyse the spatial extent over which RTM elevations and terrain corrections must be evaluated. We also analyse the influence of GDEM spatial resolutions on the accuracy of terrain effects to choose the sufficient one for Niger. We analysed the influence of height discrepancies between gravity stations and GDEM, on terrain effects. RTM effects and terrain corrections are computed at gravity stations and regular grid nodes and finally recommendation are given for further implementations of the results.

\section{Materials and methods}

\subsection{Study area and elevation data}

The study area is located between $11^{\circ}$ to $24^{\circ}$ North and $-0.5^{\circ}$ to $16.5^{\circ}$ East, and covers the Niger Republic, in the Central West Africa. The elevations vary weakly in Niger, from 200 meters in Niger River near Benin border (southwest) to about 2022 meters (Idoûkâl-n-Taghès Mount) in the Central-North area (Air Mountains). The maximum and mean slopes from SRTM v4.1(Jarvis et al., 2008) are $63.16^{\circ}$ and $1.5^{\circ}$ respectively in Niger. For the study area, the highest elevations, about $3000 \mathrm{~m}$, and rugged areas, are in the Hoggar (Algeria) and Tibesti (Chad) Mountains. The geology of Niger can be summarized as few basement zones, exposed in Liptako and Aïr Massif, and large sedimentary basins: Iullemeden and Lake Chad (Greigert \& Pougnet, 1965). The study area and specific regions are presented in Figure 1, with elevations from SRTM v4.1.

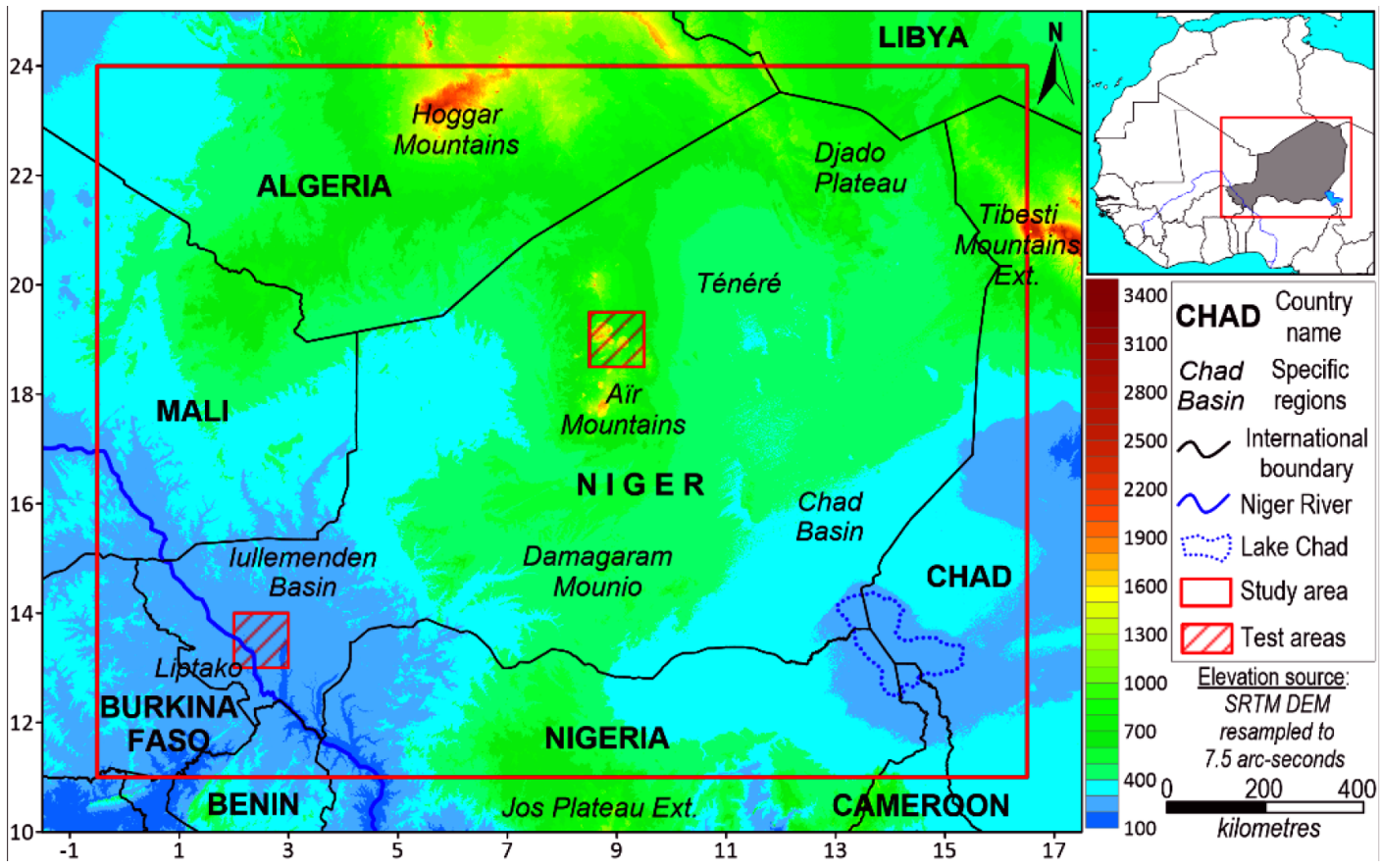

Figure 1. Study area, test areas and elevations from SRTM GDEM 


\subsection{Gravity data}

The terrestrial gravity data cover $0^{\circ}$ to $16^{\circ}$ East and $11^{\circ}$ to $24^{\circ}$ North. They are provided by the International Gravimetric Bureau (Bureau Gravimétrique International [BGI], 2015), after gross error removal we retained 8393 gravity stations. We also retrieve 1783 gravity stations from ORSTOM (Office de Recherche Scientifique et Technique Outre Mer) report (Rechenmann, 1966). Figure 2 presents the spatial distribution of gravity stations in the study area.

\subsection{Residual Terrain Model and gravimetric terrain corrections}

The RTM effect on gravity or the direct effect is approximated by the Bouguer plate taken between the true and the mean elevation surfaces minus the classical terrain corrections (Forsberg, 1984):

$$
\Delta g_{R T M} \approx 2 \pi G \rho\left(h-h_{r e f}\right)-t_{c},
$$

where $h$ and $h_{\text {ref }}$ are the heights of the true and mean elevations of the computation point respectively, with $G$ the gravitational constant and $\rho$ the topographic density. The classical terrain corrections $t_{c}$ are given at a point $\mathrm{P}\left(x, y, h_{P}\right)$ by (Forsberg, 1984):

$$
G \rho \int_{x_{1}}^{t_{c}} \int_{y_{1}}^{x_{2}} \int_{z_{1}} \frac{z-h_{p}}{\left(\left(x-x_{P}\right)^{2}+\left(y-y_{P}\right)^{2}+\left(z-h_{P}\right)^{2}\right)^{3 / 2}} d x d y d z .
$$

The terrain corrections were computed using templates (Hammer, 1939; Hayford \& Bowie, 1912), these methods are abandoned and replaced by the use of DEMs. RTM and terrain corrections are jointly illustrated in Figure 3.

The shifting of masses underlying the gravity reductions changes the gravity potential and, hence the geoid/quasigeoid, called the indirect effect. The Stokes'/ Molodensky's formula leads to the co-geoid, a slightly different surface to the geoid, which is specific to every gravity reduction (Heiskanen \& Moritz, 1967). The indirect effect is computed by applying the Brun's formula, according to RTM, the expression is (Forsberg, 1984):

$$
\begin{aligned}
& \zeta_{R T M}=\frac{\delta W}{\gamma}= \\
& \frac{G \rho}{\gamma} \int_{-\infty}^{+\infty} \int_{-\infty}^{+\infty} \int_{h_{\text {ref }}}^{h} \frac{1}{\sqrt{\left(x-x_{P}\right)^{2}+\left(y-y_{P}\right)^{2}+\left(z-h_{P}\right)^{2}}} d x d y d z,
\end{aligned}
$$

where $\delta W$ is the change of potential at the geoid and $\gamma$ the normal gravity. The integrals (2) and (3) are evaluated using rectangular prisms (Nagy, Papp, \& Benedek, 2000) or tesseroid (Grombein, Seitz, \& Heck, 2013; Seitz \& Heck, 2001). To reduce the computation time, high-resolution GDEM is used with the exact formula in the inner zone around the computation point out to radius $R_{1}$, and

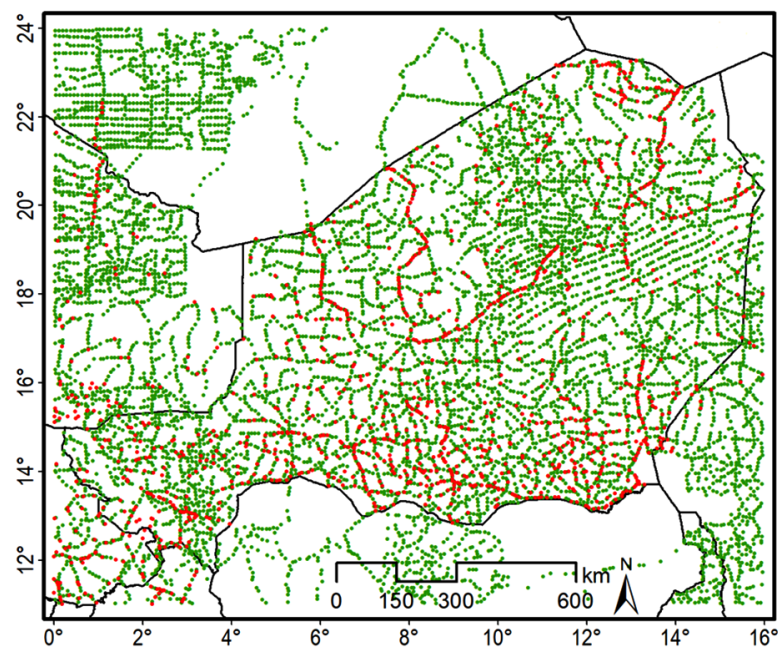

Figure 2. Terrestrial gravity data: BGI (Red), ORSTOM (Green)

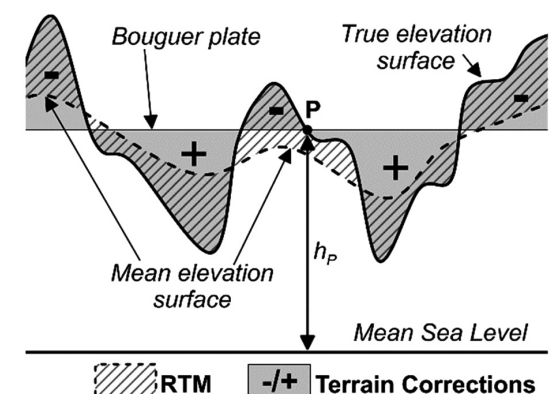

Figure 3. Residual Terrain Model (RTM) and terrain corrections (Forsberg, 1984)

coarser GDEM is used in the outer zone with approximate formula to a radius $R_{2}$ (Forsberg, 1984). The real topography is subject to mass-density anomalies, with respect to the standard rock density $\rho=2670 \mathrm{~kg} / \mathrm{m}^{3}$, sufficient information can improve the gravity field modelling and RTM effects (Hirt et al., 2010). We used the standard rock density in our study.

We used the Gravsoft module TC (Forsberg \& Tscherning, 2008) for the computation of RTM effects and terrain corrections, the Fortran program source have been modified and recompiled to extend the array size in order to support larger data. In addition of gravity stations, we created a grid of 1.5 arc-minute $\left(0.025^{\circ}\right)$ spacing and elevations were extracted from SRTM GDEM at grid nodes.

\subsection{Computation of mean elevation surfaces and coarse GDEM}

The GGM maximum degree of truncation $l_{\max }$ is associated with a shortest resolvable wavelength $\lambda$ or translated into a corresponding spatial scale as the half-wavelength $\lambda / 2$ at Earth's surface according to (Seeber, 2003):

$$
\lambda(\mathrm{km})=\frac{40,000}{l_{\max }} .
$$


The high-resolution GGMs like EGM2008 (Pavlis et al., 2012), GECO (Gilardoni, Reguzzoni, \& Sampietro, 2015) and EIGEN-6C4 (Förste et al., 2014), are complete to spherical harmonic degree and order (d/o) 2,190, corresponding to $\sim 9 \mathrm{~km}$ of spatial resolution, depending on latitude. On other hand, the most recent spatial gravity mission was expected to give $1-2 \mathrm{~cm}$ and $1-2 \mathrm{mgal}$ as geoid and gravity anomaly precisions at $\mathrm{d} / \mathrm{o} 200$ or $\sim 100 \mathrm{~km}$ of spatial scale, corresponding to medium- and long-wavelengths (Drinkwater, Floberghagen, Haagmans, Muzi, \& Popescu, 2003). Commonly, the RCR procedure uses GGMs truncated to medium- and long-wavelengths.

We used modules SELECT and TCGRID to compute the mean elevation surfaces by low-pass filtering of SRTM GDEM, following the procedure presented in Gravsoft tutorial (Forsberg \& Tscherning, 2008). We resampled the GDEM to $0.1^{\circ}$ resolution and applied the moving average on a $9 \times 9(\sim 100 \mathrm{~km})$ window. For $\sim 9 \mathrm{~km}$ spatial scale, we resampled the GDEM to 1 arc-minute and then we applied the moving average on a $5 \times 5(\sim 9.3 \mathrm{~km})$ window.

The DTM2006.0 is spherical harmonic model of Earth's topography, made available by the EGM2008 development team (Pavlis, Factor, \& Holmes, 2007) and used in numerous studies (Hirt et al., 2010; Hirt, Gruber, \& Featherstone, 2011). We computed the mean elevation surfaces corresponding to d/o 200 and 2,190 using the calculation service of the International Centre for Global Earth Models (ICGEM) (Barthelmes \& Köhler, 2016).

The study area was extended by 1 degree in all directions, covering $-1.5^{\circ}$ to $17.5^{\circ}$ of longitude and $10^{\circ}$ to $25^{\circ}$ of latitude. We compared the results of low-pass filter and DTM2006.0 by simple differences and cross section profiles. The statistics in terms of minimum (Min), maximum (Max), Mean, standard deviation (STD) and root mean square (RMS) are presented. The 30 arc-seconds resolution is used as coarse GDEM for the computations of terrain effects.

\subsection{Integration radius}

Studies had been performed on the choice of $R_{1}$ and $R_{2}$ (Ismail, 2016). $R_{1}$ has no influence on the geoid precision, but on the computation time, a value lower than $20 \mathrm{~km}$ (Hwang, Wang, \& Hsiao, 2003) and 6 to $7 \mathrm{~km}$ (Ismail, 2016 ) is sufficient for a precision of $0.1 \mathrm{mGal}$ in terrain corrections. $R_{2}$ varies from 22.4 to $200 \mathrm{~km}$ in literature, a value lower than $200 \mathrm{~km}$ is sufficient for $0.1 \mathrm{mGal}$ (Hwang et al., 2003; Ismail, 2016), at least $200 \mathrm{~km}$ for few $\mathrm{mm}$ of precision on the geoid (Hirt et al., 2010) and greater than $200 \mathrm{~km}$ according to Kloch \& Krynski (2008).

We chose two test points, one in low-lying region and another in mountainous area with heights of $179 \mathrm{~m}$ and $1320 \mathrm{~m}$ respectively. The near zone generates the largest RTM quasigeoid and terrain corrections contributions. We followed the method in Hirt et al. (2010) to determine the value of $R_{2}$ beyond what we could obtain reasonably stable values with remaining convergence errors at the levels of $0.1 \mathrm{mgal}$ and a few mm. We fixed $R_{1}$ to $10 \mathrm{~km}$, computed the contributions of the near zone to $60 \mathrm{~km}$ and presented the contributions as functions of $R_{2}$ up to $300 \mathrm{~km}$. For $R_{1}$, we followed the procedure in Ismail (2016), we fixed $R_{2}$ to $200 \mathrm{~km}$, varied $R_{1}$ from 5 to $55 \mathrm{~km}$ as reference and analysed the differences of terrain corrections and indirect effects with respect to those of the reference radius $(55 \mathrm{~km})$. The tests are performed with the mean elevation surface of $\sim 100 \mathrm{~km}$ spatial scale.

\subsection{GDEM spatial resolutions and terrain effects}

In this section, we investigate the sufficient spatial resolution for good precision of terrain effects in Niger. We computed RTM effects and terrain corrections at grid nodes in two test areas with 1 arc-second (NASA-JPL, 2013), 3 arc-seconds (Jarvis et al., 2008) and resampled versions to $7.5,15,30$ and 60 arc-seconds spatial resolutions of SRTM GDEM. We used the mean elevation surface of $\sim 100 \mathrm{~km}$ spatial scale. The first test area is located in lowlying region near the Niger River $\left(13^{\circ}\right.$ to $14^{\circ}$ North and $2^{\circ}$ to $3^{\circ}$ East) and the second in Aïr mountains $\left(18.5^{\circ}\right.$ à $19.5^{\circ}$ North and $8.5^{\circ}$ à $9.5^{\circ}$ East) (Figure 1 ). We set 1 arc-second as reference and analysed the differences of terrain effects by spatial resolution (5):

$$
\Delta X=X_{1 S}-X_{\text {Other }},
$$

where $\Delta X$ is the difference, $X_{1 S}$ stands for terrain effects computed from 1 arc-second resolution and $X_{\text {Other }}$ from others. Statistics are presented.

\subsection{Computation of RTM effects at grid nodes and gravity stations}

The direct and indirect effects, according to RTM, and terrain corrections are computed at each gravity station and grid nodes for the whole study area with mean reference topographic surfaces of $100 \mathrm{~km}$ and $9 \mathrm{~km}$ spatial scales respectively. We used 3 arc-seconds SRTM GDEM (Jarvis et al., 2008), and due to computer limitations, the study area was divided into $3^{\circ} \times 3^{\circ}$ small zones. The statistics and grid maps were presented with specific focus on the distributions of terrain effects in Niger.

\subsection{Impact of height discrepancies on RTM effects and terrain corrections}

In this section, we analysed the influence of height discrepancy between gravity stations and GDEM on the accuracy of RTM effects and terrain corrections. We built an alternative gravity database, we replaced the heights of gravity stations by those of SRTM GDEM and recomputed the terrain effects with the mean elevation surface of $\sim 100 \mathrm{~km}$ spatial scale. The results are compared with those of the original database by simple difference (6):

$$
\Delta Y=Y_{\text {Original }}-Y_{\text {Alternative }},
$$

where $Y$ stands for altitude $H$, direct effect $\Delta g_{R T M}$, terrain correct $t_{c}$ and indirect $\zeta_{R T M}$. We analysed the differences by basic statistics and Pearson correlation test at $5 \%$ of confidence level. 


\section{Results and discussions}

\subsection{Mean elevation surfaces}

Figures $4 \mathrm{a}$ and $4 \mathrm{~b}$ show the mean elevation surface corresponding to $\sim 100$ of spatial scale or d/o 200 computed from low-pass filter and its difference with that derived from topography spherical harmonic model, respectively. Figure 4c and Figure $4 \mathrm{~d}$ show the equivalent results for $\sim 9 \mathrm{~km}$ spatial scale or $\mathrm{d} / \mathrm{o} 2,190$. It is evident that the surface corresponding to $\mathrm{d} / \mathrm{o} 200$ is smother. Table 1 reports the descriptive statistics of the mean elevation surfaces and their differences.

The absolute difference values reach $200 \mathrm{~m}$, with RMS of 32.40 and $8.81 \mathrm{~m}$ respectively for $\mathrm{d} / \mathrm{o} 200$ and 2,190. On Figure 4e (cf. cross section profile A-B, Figure 4a), the spherical harmonic method gives more spectral details for d/o 200. Cross sections C-D and E-F (cf. Figure 4c) are located in low-lying and rugged areas respectively. On Figure $4 \mathrm{f}$ and Figure 4g, low-pass filter solution presents more spectral details for $\mathrm{d} / \mathrm{o} 2190$. There are also horizontal shifts between the mean elevation surfaces. To better construct RTM elevations taking into account local terrain characteristics, we considered the reference surfaces determined by the filter low pass.

Table 1. Statistics of mean elevation surfaces and their differences. $\mathrm{LPF}=$ Low-pass filter. $\mathrm{SH}=$ Spherical harmonic

\begin{tabular}{|c|c|c|c|c|c|c|}
\hline d/o & Method & Min & Max & Mean & STD & RMS \\
\hline \multirow{3}{*}{200} & LPF & 150.30 & 1748.23 & 484.51 & 233.08 & 537.66 \\
\cline { 2 - 7 } & SH & 125.05 & 1715.17 & 483.32 & 237.70 & 538.61 \\
\cline { 2 - 7 } & $\begin{array}{c}\text { LPF }- \\
\text { SH }\end{array}$ & -192.29 & 229.30 & 0.627 & 32.39 & 32.40 \\
\hline \multirow{2}{*}{2190} & LPF & 115.27 & 2534.77 & 483.82 & 244.14 & 541.93 \\
\cline { 2 - 7 } & SH & 104.23 & 2519.95 & 483.27 & 244.55 & 541.62 \\
\cline { 2 - 7 } & $\begin{array}{c}\text { LPF - } \\
\text { SH }\end{array}$ & -205.327 & 138.80 & 0.453 & 8.798 & 8.81 \\
\hline
\end{tabular}
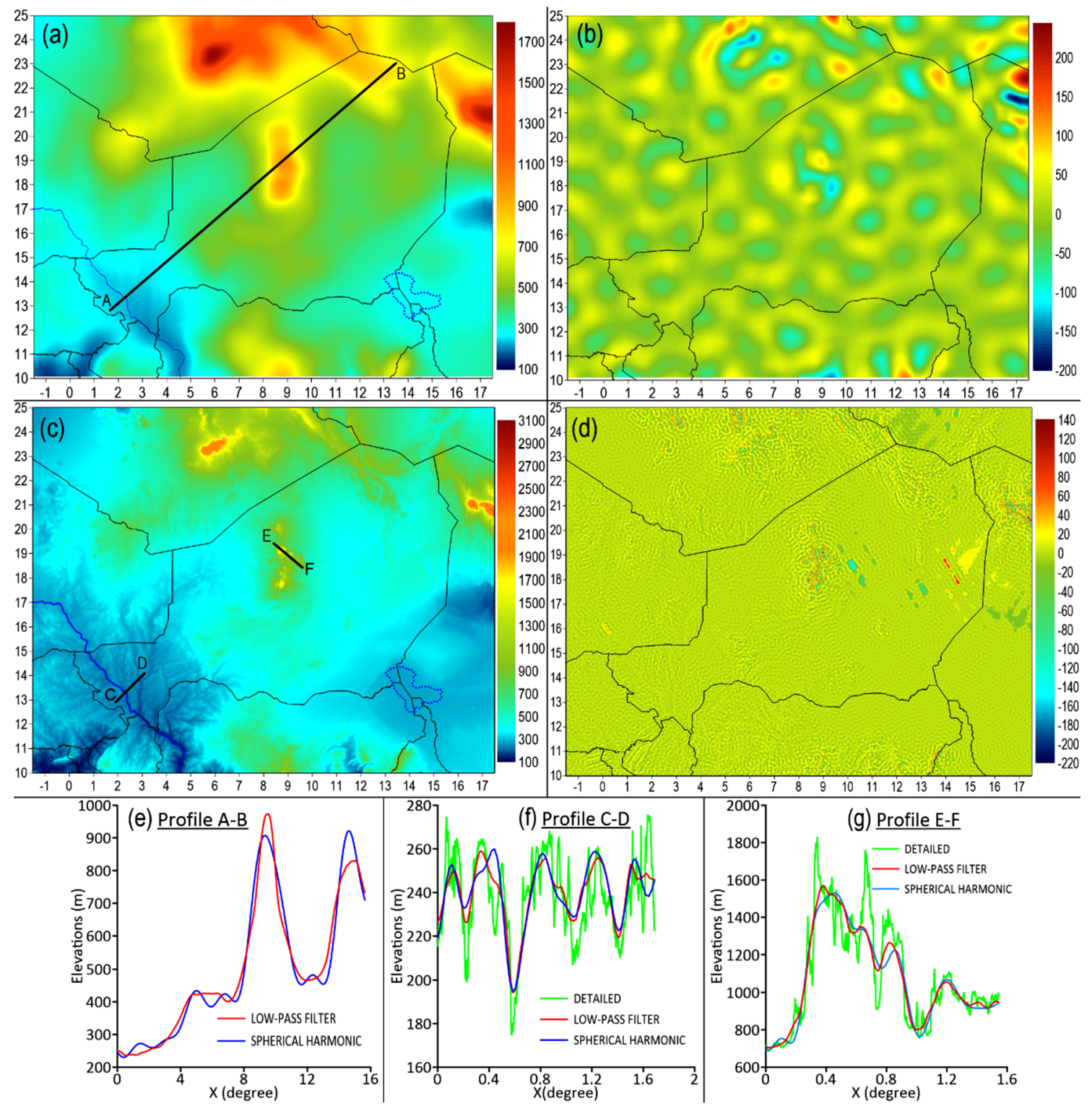

Figure 4. Reference surfaces from low-pass filtering of GDEM and their differences with those derived from topographic spherical harmonic in metres: $a-d / o$ 200; b - Difference for d/o 200; c - d/o 2190; d - Difference for d/o 2190; e - Cross section profile A-B (cf. Figure 4a); f - Cross section profile C-D (cf. Figure 4c); g - Cross section profile E-F (cf. Figure 4c) 


\subsection{Integration radius}

The RTM contribution to quasigeoid (indirect effect) and the terrain corrections as function of integration radius $R_{2}$ are shown in Figures $5 \mathrm{a}$ and $5 \mathrm{c}$ for the test points in low-lying region and mountainous area respectively. The values are more important in the near $60 \mathrm{~km} \mathrm{ra-}$ dius around the test points, oscillating values of RTM and true elevations reflect low-lying and mountainous patterns, they propagate into indirect effect and terrain corrections values. The amplitudes are of $3-5 \mathrm{~mm}$ and 0.01-0.02 mgal at wavelengths of 15-20 km in low-lying region (Figure 5a), at $0.02 \mathrm{mgal}$ and $3 \mathrm{~mm}$ levels, the values are stable beyond $R_{2}=100 \mathrm{~km}$. In mountainous area, the amplitudes are of $1-5 \mathrm{~cm}$ and $0.5 \mathrm{mgal}$ at wavelengths of $15-20 \mathrm{~km}$ (Figure $5 \mathrm{c}$ ), the values are stable beyond $R_{2}=190 \mathrm{~km}$.

With $55 \mathrm{~km}$ as reference value, the influence of $R_{1}$ is negligible on the RTM height anomalies and terrain corrections at the point test point in low-lying region (Figure $5 \mathrm{~b}$ ). In mountainous area (Figure $5 \mathrm{~d}$ ), from $R_{1}=$ $5 \mathrm{~km}$, the value of differences are $0.035 \mathrm{mgal}$ and $5 \mathrm{~mm}$ respectively for indirect effect and terrain corrections, $R_{1}=$ $10 \mathrm{~km}$ is sufficient for $0.01 \mathrm{mgal}$ and $2 \mathrm{~mm}$ of precisions. Low-lying regions predominate over Niger republic, $R_{1}=$ $10 \mathrm{~km}$ and $R_{2}=200 \mathrm{~km}$ are sufficient, all computations are performed with these values.

\subsection{RTM effects and GDEM resolutions}

There are 1681 grid nodes for each test area. The descriptive statistics of the terrain effects and their differences per spatial resolution are shown in Tables 2, 3 and 4 respectively for terrain corrections, direct effect and indirect effect. The quantities are more important in mountainous area. For the differences, all statistical measures (value range, Mean, STD and RMS) increase when the resolution becomes lower for both test areas.

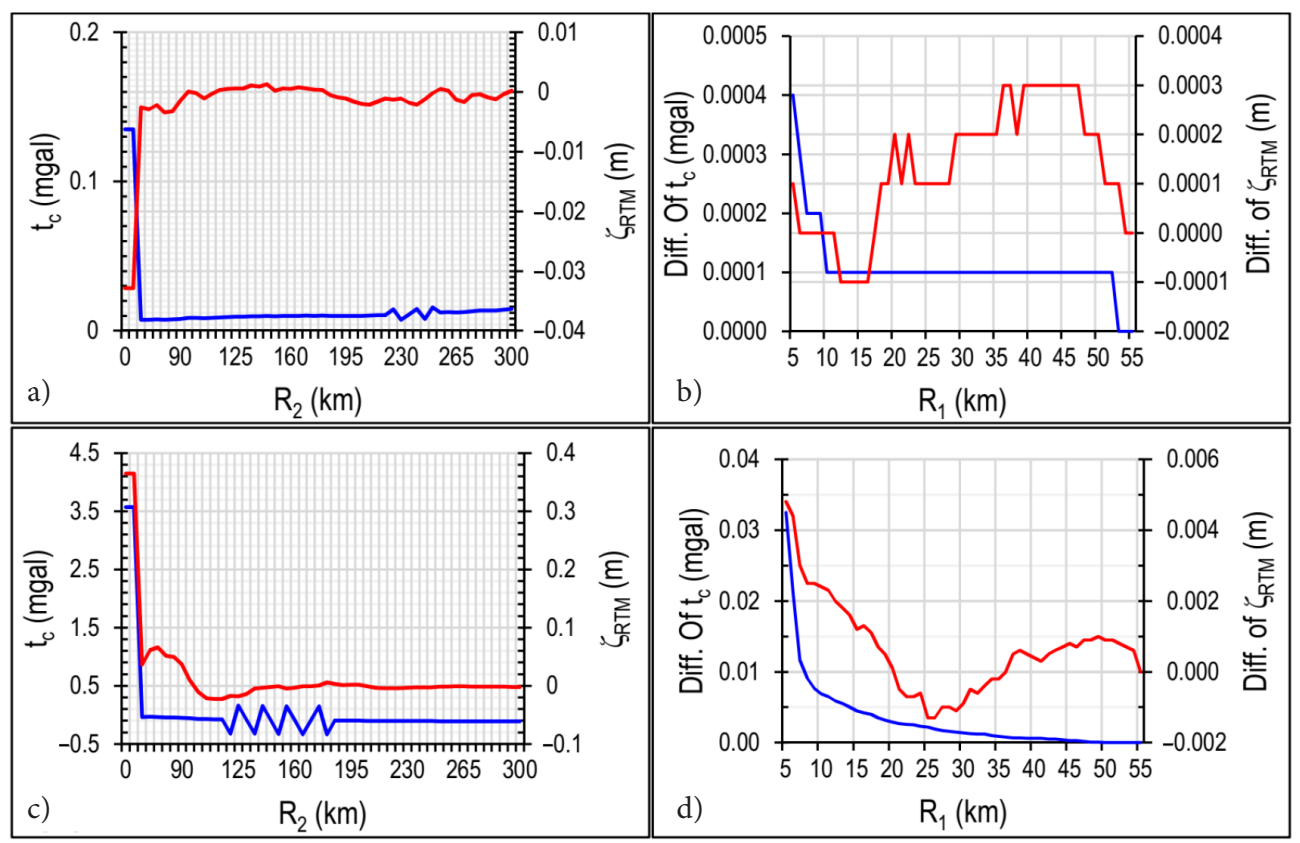

Figure 5. RTM height anomalies and terrain corrections as functions of computation radius $R_{2}$ for $R_{1}=15 \mathrm{~km}$ : a) - low-lying region; b) - low-lying region; c) - Mountainous area. Difference of RTM effects and terrain corrections as function of computation radius $R_{1}$ for $R_{2}=200 \mathrm{~km}$; ) - Mountainous area. Blue line $=$ Terrain corrections. Red line = Indirect effect

Table 2. Statistics of terrain corrections and their differences (mgal) by GDEM resolutions

\begin{tabular}{|l|c|c|c|c|c|c|c|c|c|c|}
\hline & \multicolumn{9}{|c|}{ Niger River } & \multicolumn{4}{c|}{ Aïr } \\
\cline { 2 - 12 } & Min & Max & Mean & STD & RMS & Min & Max & Mean & STD & RMS \\
\hline $\mathrm{X}_{1 \mathrm{~S}}$ & 0.00 & 0.32 & 0.05 & 0.06 & 0.07 & 0.00 & 19.19 & 1.48 & 2.13 & 2.59 \\
\hline $\mathrm{X}_{3 \mathrm{~S}}$ & 0.00 & 0.33 & 0.05 & 0.05 & 0.07 & 0.00 & 20.97 & 1.47 & 2.18 & 2.62 \\
\hline $\mathrm{X}_{1 \mathrm{~S}}-\mathrm{X}_{3 \mathrm{~S}}$ & -0.06 & 0.06 & 0.00 & 0.01 & 0.01 & -1.78 & 2.67 & 0.01 & 0.26 & 0.26 \\
\hline $\mathrm{X}_{1 \mathrm{~S}}-\mathrm{X}_{7.5 \mathrm{~S}}$ & -0.05 & 0.18 & 0.01 & 0.01 & 0.02 & -2.90 & 7.56 & 0.21 & 0.58 & 0.62 \\
\hline $\mathrm{X}_{1 \mathrm{~S}}-\mathrm{X}_{15 \mathrm{~S}}$ & -0.02 & 0.21 & 0.01 & 0.02 & 0.02 & -8.52 & 10.88 & 0.39 & 1.05 & 1.12 \\
\hline $\mathrm{X}_{1 \mathrm{~S}}-\mathrm{X}_{30 \mathrm{~S}}$ & -0.08 & 0.15 & 0.01 & 0.02 & 0.02 & -5.80 & 12.83 & 0.46 & 1.32 & 1.40 \\
\hline $\mathrm{X}_{1 \mathrm{~S}}-\mathrm{X}_{60 \mathrm{~S}}$ & -0.07 & 0.21 & 0.01 & 0.02 & 0.03 & -0.78 & 14.48 & 0.69 & 1.45 & 1.61 \\
\hline
\end{tabular}


Table 3. Statistics of direct effects and their differences (mgal) by GDEM spatial resolution

\begin{tabular}{|c|c|c|c|c|c|c|c|c|c|c|}
\hline & \multicolumn{5}{|c|}{ Niger River } & \multicolumn{5}{|c|}{ Aïr } \\
\hline & Min & Max & Mean & STD & RMS & Min & $\operatorname{Max}$ & Mean & STD & RMS \\
\hline $\mathrm{X}_{1 \mathrm{~S}}$ & -7.05 & 4.04 & -0.3 & 2.58 & 2.6 & -24.59 & 96.93 & 4.04 & 23.81 & 24.14 \\
\hline $\mathrm{X}_{3 \mathrm{~S}}$ & -7.05 & 4.07 & -0.29 & 2.57 & 2.59 & -24.73 & 96.69 & 4.03 & 23.8 & 24.13 \\
\hline $\mathrm{X}_{1 \mathrm{~S}-} \mathrm{X}_{3 \mathrm{~S}}$ & -0.39 & 0.29 & -0.01 & 0.08 & 0.08 & -2.05 & 4.64 & 0.01 & 0.39 & 0.39 \\
\hline $\mathrm{X}_{1 \mathrm{~S}}-\mathrm{X}_{7.5 \mathrm{~S}}$ & -0.98 & 1.24 & -0.01 & 0.23 & 0.23 & -19.62 & 11.05 & -0.15 & 1.98 & 1.98 \\
\hline $\mathrm{X}_{1 \mathrm{~S}}-\mathrm{X}_{15 \mathrm{~S}}$ & -1.32 & 1.7 & -0.01 & 0.29 & 0.29 & -25.79 & 12.93 & -0.36 & 2.77 & 2.80 \\
\hline $\mathrm{X}_{1 \mathrm{~S}}-\mathrm{X}_{30 \mathrm{~S}}$ & -3.68 & 4.91 & 0.04 & 0.71 & 0.71 & -28.04 & 34.72 & -0.39 & 4.98 & 5.00 \\
\hline $\mathrm{X}_{1 \mathrm{~S}}-\mathrm{X}_{60 \mathrm{~S}}$ & -3.98 & 6.68 & 0.03 & 0.83 & 0.83 & -35.50 & 38.26 & -0.58 & 5.67 & 5.70 \\
\hline
\end{tabular}

Table 4. Statistics of indirect effect and their differences (metres) by GDEM spatial resolutions

\begin{tabular}{|c|c|c|c|c|c|c|c|c|c|c|}
\hline & \multicolumn{5}{|c|}{ Niger River } & \multicolumn{5}{|c|}{ Aïr } \\
\hline & Min & $\operatorname{Max}$ & Mean & STD & RMS & Min & $\operatorname{Max}$ & Mean & STD & RMS \\
\hline $\mathrm{X}_{1 \mathrm{~S}}$ & -0.061 & 0.017 & -0.017 & 0.021 & 0.027 & -0.058 & 1.233 & 0.317 & 0.287 & 0.427 \\
\hline $\mathrm{X}_{3 \mathrm{~S}}$ & -0.061 & 0.017 & -0.018 & 0.021 & 0.027 & -0.057 & 1.233 & 0.319 & 0.286 & 0.428 \\
\hline$X_{1 S}-X_{3 S}$ & 0.000 & 0.001 & 0.000 & 0.000 & 0.000 & -0.012 & 0.006 & -0.002 & 0.003 & 0.004 \\
\hline $\mathrm{X}_{1 \mathrm{~S}}-\mathrm{X}_{7.5 \mathrm{~S}}$ & -0.001 & 0.001 & 0.000 & 0.000 & 0.000 & -0.016 & 0.014 & 0.001 & 0.003 & 0.003 \\
\hline $\mathrm{X}_{1 \mathrm{~S}}-\mathrm{X}_{15 \mathrm{~S}}$ & -0.001 & 0.002 & 0.000 & 0.000 & 0.001 & -0.034 & 0.046 & 0.001 & 0.008 & 0.008 \\
\hline $\mathrm{X}_{1 \mathrm{~S}}-\mathrm{X}_{30 \mathrm{~S}}$ & -0.004 & 0.004 & 0.001 & 0.001 & 0.001 & -0.044 & 0.049 & 0.000 & 0.010 & 0.010 \\
\hline$X_{1 S}-X_{60 S}$ & -0.003 & 0.008 & 0.001 & 0.001 & 0.001 & -0.030 & 0.052 & 0.001 & 0.005 & 0.005 \\
\hline
\end{tabular}

In low-lying area test, the absolute values of differences of terrain corrections are lower than 0.5 mgal (Table 2), low-resolutions are sufficient to have a good accuracy. In Air test area, the RMS of differences varies from 0.26 to $1.61 \mathrm{mgal}, 3 \mathrm{arc}-\mathrm{sec}$ onds resolution showed the lower value range of differences ( -1.78 to $2.67 \mathrm{mgal}$ ).

Near Niger River, the RMS of differences for the direct effect varies from 0.08 to $0.83 \mathrm{mgal}$ and the bias is negligible (Table 3). In Aïr test area, values range from 0.39 to $5.70 \mathrm{mgal}$ and -0.58 to $0.01 \mathrm{mgal}$ respectively for RMS and Mean. 3 arc-seconds resolution showed the smallest difference values in both test areas, whereas the values exceed 10 mgal for lower resolutions in the mountainous area.

For the indirect effect (Table 4), the RMS and Mean values of differences do not exceed $1 \mathrm{~mm}$ for all resolutions in Niger River area. In Aïr test area, at $\mathrm{cm}$ level, the statistics are the same for all resolutions, the absolute values of differences do not exceed $5 \mathrm{~cm}$, and the RMS values of differences vary from 3 to $10 \mathrm{~mm}$.

With 1 arc-second as reference and resolutions from 3 to 60 arc-seconds, the expected accuracy by RMS is $0.08-$ 0.83 mgal for the direct effect and 0.01-0.03 mgal for the terrain corrections, in the low-lying area. The influence of GDEM resolutions on the indirect effect is negligible in low-lying regions, the expected improvement is of $10 \mathrm{~mm}$ order with respect to lower resolutions in mountainous areas. In the mountainous area, the precisions is 0.39$5.70 \mathrm{mgal}$ for the direct effect and $0.26-1.61 \mathrm{mgal}$ for the terrain corrections. In the whole study area, 3 arc-seconds resolution is sufficient to have good precisions.

\subsection{RTM effects - terrain corrections - grid maps}

The descriptive statistics of terrain corrections and RTM effects corresponding to $\sim 100 \mathrm{~km}$ spatial scale at 10176 gravity stations are reported in Table 5 . We focused on grid data, the statistics of terrain effects at 354801 grid nodes are shown in Table 6 , and the point values are converted into raster grids with the same resolution, 1.5 arcminute. The RTM effects are more important for the mean elevation surface of $\sim 100 \mathrm{~km}$ spatial scale. The RTM contributions to quasigeoid are lower than $10 \mathrm{~cm}$ for mean elevation surface of $\sim 9 \mathrm{~km}$, whereas values reach $1.8 \mathrm{~m}$ for $\sim 100 \mathrm{~km}$ spatial scale. The direct effect varies from -53.92 to $48.46 \mathrm{mgal}$ and -31.14 to $155.75 \mathrm{mgal}$ respectively for $\sim 9 \mathrm{~km}$ and $\sim 100 \mathrm{~km}$ spatial scales. Terrain corrections do not exceed 30 mgal.

Table 5. Statistics of RTM effects and terrain corrections at gravity stations

\begin{tabular}{|l|c|c|c|c|c|}
\hline \multicolumn{1}{|c|}{ Quantities } & Min & Max & ME & STD & RMS \\
\hline $\begin{array}{l}\text { Station height } \\
(\mathrm{m})\end{array}$ & 143.00 & 1996.00 & 425.02 & 143.10 & 448.46 \\
\hline$\Delta g_{R T M}(\mathrm{mgal})$ & -37.00 & 25.29 & -1.51 & 3.38 & 3.70 \\
\hline$t_{c}$ (mgal) & 0.00 & 14.53 & 0.23 & 0.59 & 0.63 \\
\hline$\zeta_{R T M}(\mathrm{~m})$ & -0.306 & 1.473 & -0.014 & 0.068 & 0.069 \\
\hline
\end{tabular}

Figure $6 \mathrm{a}$ and Figure $6 \mathrm{~b}$ show the grid maps of direct and indirect effects respectively for $\sim 100 \mathrm{~km}$ spatial scale, those corresponding to $\sim 9 \mathrm{~km}$ spatial scale are displayed in 
Figure $6 \mathrm{c}$ and Figure 6d. RTM effects and terrain corrections (see Figure 7) are globally low and correlated with steep topographic gradients. Relatively large values are exposed in: Hoggar Mountains (Algeria), Aïr Mountains (Central North Niger) and Tibesti Mountains extension (Chad).

The grids are clipped over Niger giving 161247 grid nodes, the statistics and histograms are shown in Table 7 and Figure 8 respectively. For d/o 2190, 98.44\% of indirect effects are lower than $1 \mathrm{~cm}$ and $98.2 \%$ of direct effects are lower than 5 mgal. For d/o 200, 85.87\% of indirect effects are lower than $10 \mathrm{~cm}$, and $12.75 \%$ range from 10 to $30 \mathrm{~cm}$, $89.77 \%$ of direct effects are lower than $5 \mathrm{mgal}$ and $6.66 \%$ range from 5 to $10 \mathrm{mgal}$. $98.77 \%$ of terrain corrections are lower than $1 \mathrm{mgal}, 1.105 \%$ range from 1 to $5 \mathrm{mgal}$ in Niger. These results show the small changes in topography in Niger, also stated by Rechenmann (1969).

Table 6. Statistics of RTM effect at grid nodes for the computation area

\begin{tabular}{|c|l|c|c|c|c|}
\hline $\begin{array}{c}\text { Spatial } \\
\text { scale } \\
(\mathrm{km})\end{array}$ & Quantities & Min & Max & Mean & STD \\
\hline \multirow{2}{*}{$\sim 100$} & $\Delta g_{R T M}(\mathrm{mgal})$ & -31.14 & 155.75 & -0.118 & 4.93 \\
\cline { 2 - 6 } & $\zeta_{R T M}(\mathrm{~m})$ & -0.347 & 1.778 & -0.002 & 0.111 \\
\hline \multirow{2}{*}{$\sim 9$} & $\Delta g_{R T M}(\mathrm{mgal})$ & -53.92 & 48.46 & -0.08 & 1.66 \\
\cline { 2 - 6 } & $\zeta_{R T M}(\mathrm{~m})$ & -0.059 & 0.089 & -0.0002 & 0.003 \\
\hline \multirow{2}{*}{} & $t_{c}$ (mgal) & 0.00 & 28.51 & 0.106 & 0.36 \\
\hline
\end{tabular}
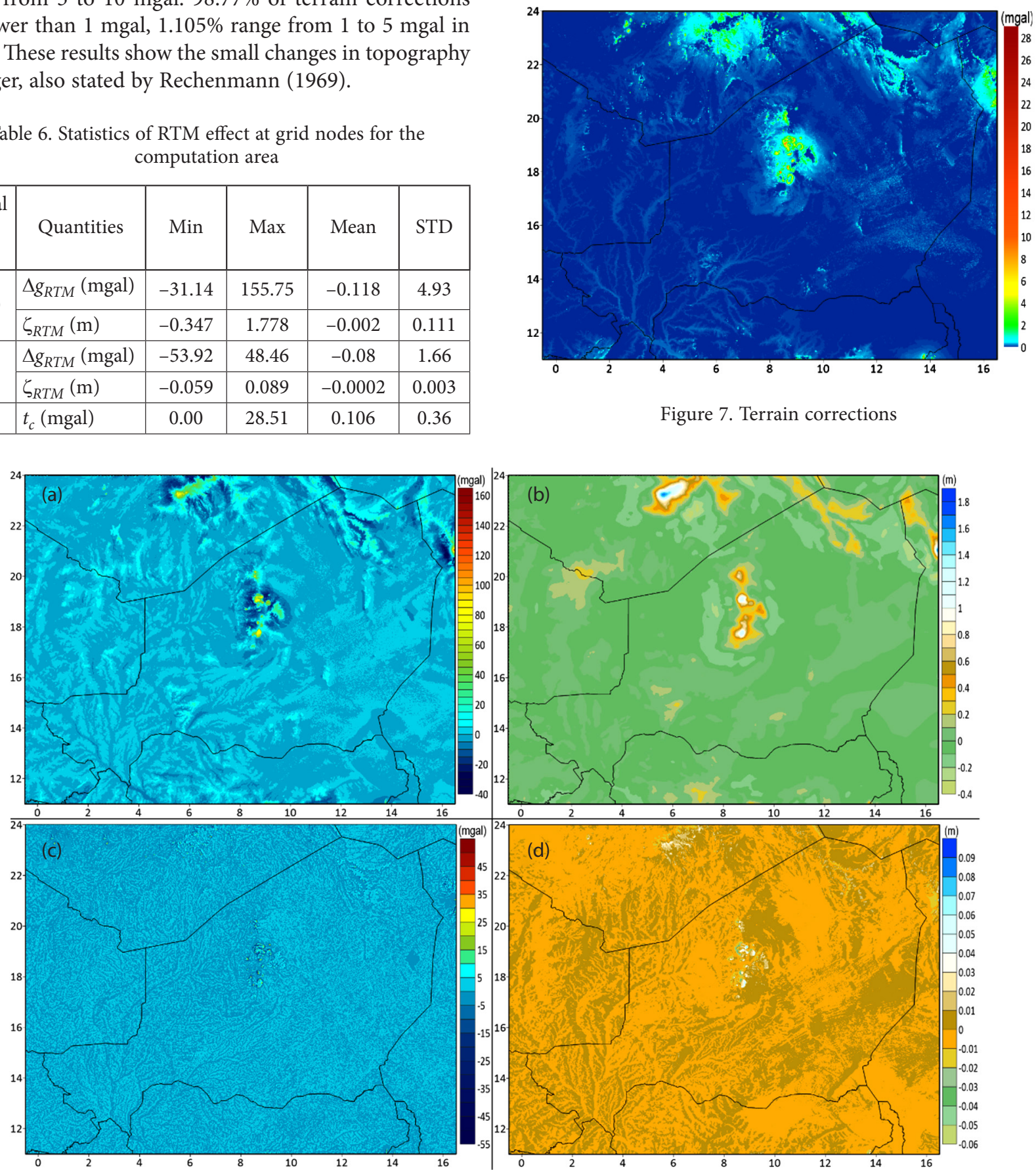

Figure 7. Terrain corrections

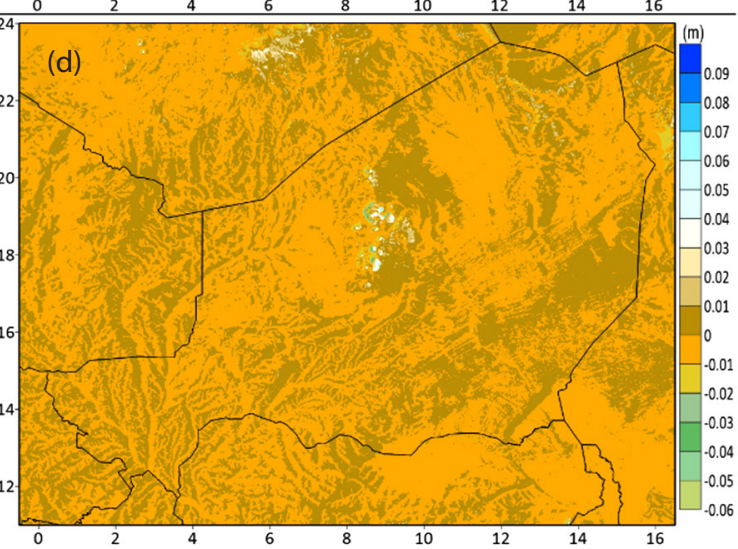

Figure 6. RTM effects: a - Direct effect and b - indirect effect for d/o 200. c - Direct effect and d - indirect effect for d/o 2190 


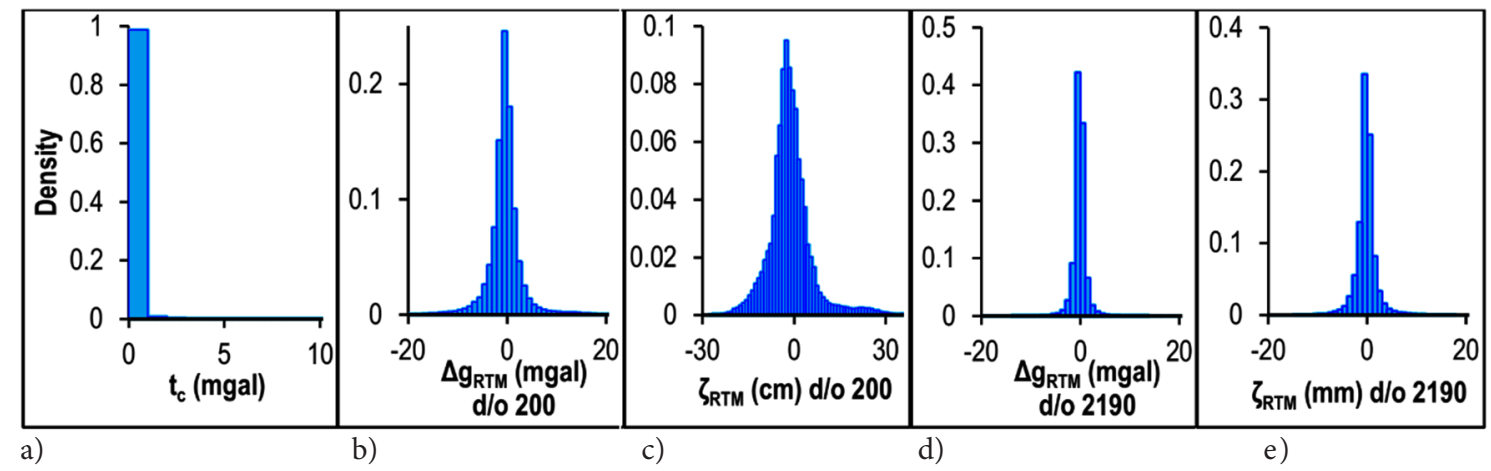

Figure 8. Distribution of RTM effects and terrain corrections over in Niger: a - Terrain correction; b - Direct effect and c - Indirect effect for d/o 200; d - Direct effect and e - Indirect effect for d/o 2190

\subsection{Impact of height discrepancies on terrain effects at gravity stations}

Table 8 reports the statistics of terrain effects for alternative gravity database and their differences with original database, corresponding to $\sim 100 \mathrm{~km}$ spatial scale. According to mean values of differences, terrain corrections are overestimated with the original database, whereas the RTM effects show the contrary, the biases are significant for terrain corrections and direct effect. The influence of height discrepancies on direct effect and terrain corrections is clearly visible in Figures $9 \mathrm{a}$ and Figure 9b, their absolute differences increase when that of height increases, the regression lines are approximated by second order polynomials. The terrain corrections are overestimated both for gravity station that is above or below GDEM. The differences of direct effect (Figure 9c) are highly correlated with those of heights, the coefficient is 0.965 , and the Bouguer plate is the main contribution, $0.1119 \mathrm{mgal} / \mathrm{m}$.

The influence of height discrepancy on indirect effects is not significant, the absolute value of difference is of $3 \mathrm{~mm}$ order and the coefficient of correlation is 0.60 . To overcome the impact of height discrepancy between the two sources of elevation, RTM effects and terrain corrections computed from the alternative database are more
Table 8. Statistics of terrain effects for alternative database and their differences with those of original database

\begin{tabular}{|c|c|c|c|c|c|c|}
\hline & Quantities & Min & Max & $\mathrm{ME}$ & STD & RMS \\
\hline \multirow{4}{*}{$\begin{array}{l}\text { Alter- } \\
\text { native } \\
\text { data- } \\
\text { bases }\end{array}$} & \begin{tabular}{|l} 
\\
(SRTM3)
\end{tabular} & 146.00 & 2102.00 & 428.91 & 141.99 & 451.80 \\
\hline & $t_{c}$ (mgal) & 0.00 & 3.94 & 0.08 & 0.14 & 0.16 \\
\hline & $\begin{array}{l}\Delta g_{R T M} \\
(\mathrm{mgal}) \\
\end{array}$ & -24.76 & 45.37 & -0.94 & 3.12 & 3.26 \\
\hline & $\zeta_{R T M}(\mathrm{~m})$ & -0.306 & 1.470 & -0.014 & 0.068 & 0.069 \\
\hline \multirow{4}{*}{$\begin{array}{l}\text { Diffe- } \\
\text { rences }\end{array}$} & $H(\mathrm{~m})$ & -170.00 & 138.00 & -3.89 & 14.12 & 14.65 \\
\hline & $t_{c}$ (mgal) & -1.55 & 14.48 & 0.15 & 0.55 & 0.57 \\
\hline & $\begin{array}{l}\Delta g_{R T M} \\
(\mathrm{mgal}) \\
\end{array}$ & -32.85 & 6.07 & -0.57 & 1.86 & 1.95 \\
\hline & $\zeta_{R T M}(\mathrm{~mm})$ & -1.200 & 3.200 & -0.017 & 0.094 & 0.096 \\
\hline
\end{tabular}

appropriate, because the GDEM better describes the terrain characteristics around gravity stations.

\section{Recommendations for further implementations over Niger}

The results of this study can be used for several purposes: complete Bouguer reduction, omission error estimate, gridding of free air anomalies and geoid determinations.

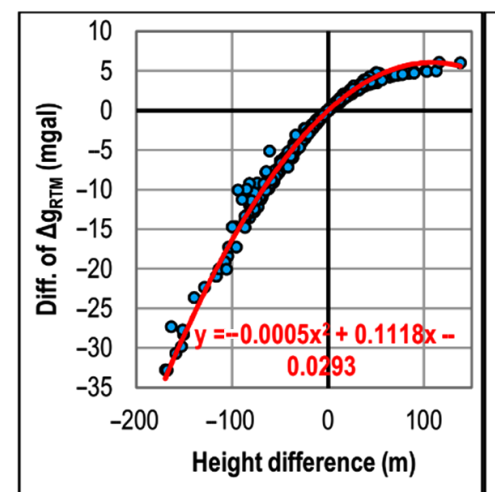

a)

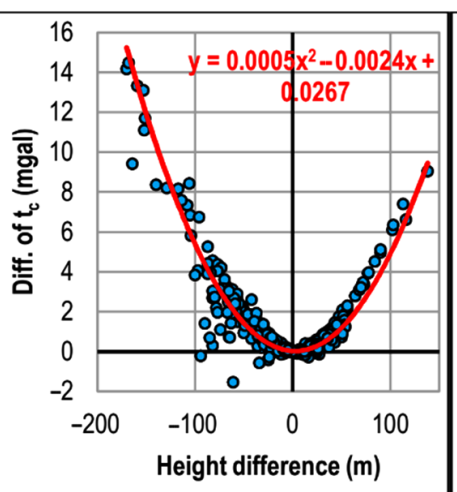

b)

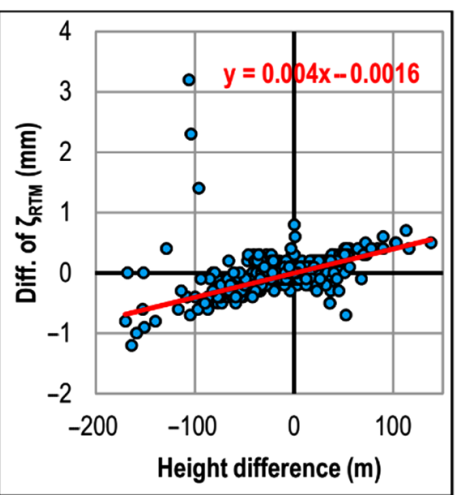

c)

Figure 9. Differences of terrain effects between original and alternative gravity databases as functions of height differences: a - Direct effect; b - Terrain correction and c - Indirect effect 


\subsection{Complete Bouguer reduction}

The terrain corrections can be used for complete Bouguer reduction at gravity stations in Niger. We digitized 18367 points of simple Bouguer gravity anomalies from Niger gravity maps, consisting of 5 sheets (Ibrahim Yahaya, El Brirchi, \& El Azzab, 2017b). The value of terrain corrections can be extracted from the grid (Figure 7) to refine the Bouguer reduction prior to the interpolation. Another way is to interpolate the point of simple Bouguer anomalies to the same resolution (1.5 arc-minute) and then add the grid of terrain corrections.

\subsection{Omission error estimate for high-resolution GGMs and gravity database densification}

The RTM effects corresponding to d/o 2190 can be combined with high-resolution GGMs to compute geoid and gravity anomaly maps over Niger and surrounding areas. The expected improvement for geoid heights is of $10 \mathrm{~cm}$ order (see Table 6). The gravity data are limited in $0^{\circ}$ to $16^{\circ}$ East and $11^{\circ}$ to $24^{\circ}$ North, and present large gaps in Libya, Algeria, Mali, Chad, Nigeria and Lake Chad. The enhanced gravity anomaly map from high-resolution GGMs combined with RTM can be used for filling gaps and the densification of the gravity database in the study area.

\subsection{Gridding of free air gravity anomalies and geoid determination}

The RTM effects corresponding to d/o 200 can be used for gravity data gridding and the determination of gravimetric geoid model by RCR process. The free-air anomalies contain high-frequency effects and are thus sensitive to aliasing during the gridding procedure (Kirby \& Featherstone, 2002). One way, is the removal of long wavelengths computed from pure satellite GGM and the direct effect (Figure 6a) from point free air anomalies. The reduced gravity anomalies are interpolated and then the grids of GGM contribution and RTM effects are restored. The reduced gravity anomalies are also used in the cross validation of gravity database, the choice of the suitable gridding method and in Stokes' formula for geoid computation. The indirect effect (Figure 6b) is the contribution of shortwavelengths to the geoid.

\section{Conclusions}

In this study, we computed and presented 1.5 arc-minute grid maps of high resolution residual terrain model (RTM) and terrain corrections over Niger republic. The RTM elevations are constructed from 3 arc-seconds resolution SRTM GDEM and mean elevation surfaces of $\sim 100 \mathrm{~km}$ and $\sim 9 \mathrm{~km}$ of spatial scales respectively. The mean elevation surfaces from low-pass filter of GDEM was adopted instead of topographic spherical harmonic derived ones. The indirect effect and the terrain corrections are evaluated out to $R_{2}=200 \mathrm{~km}$ and $R_{1}=10 \mathrm{~km}$ as outer and inner zones around each computation point. We showed that these radius and the 3 arc-seconds resolution GDEM are sufficient to obtain good precision for terrain corrections, direct and indirect effects.

The study area is characterised by low values of terrain effects because of low-regions in general, values are correlated with steep topographic gradients and relatively large values are located in rough topographic areas. In Niger, $98.44 \%$ of indirect effects do not exceed $1 \mathrm{~cm}$ and $98.2 \%$ of direct effects are lower than $5 \mathrm{mgal}$ for $\sim 9 \mathrm{~km}$ spatial scale. For $\sim 100 \mathrm{~km}$ spatial scale, $85.87 \%$ of indirect effects are lower than $10 \mathrm{~cm}$ and $89.77 \%$ of direct effects are lower than 5 mgal. $98.77 \%$ of terrain corrections are less than $1 \mathrm{mgal}$.

The height discrepancy between gravity database and GDEM leads to the overestimation of terrain corrections and influences Bouguer plate contribution to the direct effect. The heights differences are correlated with the differences of RTM effects. We suggested to use the terrain effects computed essentially with the GDEM that better describes the terrain characteristics around gravity stations.

The main contribution of this study, the first of its kind, is the modelling of terrain corrections and the shortwavelengths of the gravity field and geoid through residual terrain model approach in Niger. It is an added value for applications in geodesy and geophysics that require accurate interpretations. The selection of the optimal global geopotential model (GGM) that better describes the longwavelengths also remains a concern, validation data are available (Ibrahim Yahaya, El Brirchi, \& El Azzab, 2017a).

\section{Acknowledgements}

This work is part of the $\mathrm{PhD}$ thesis at Sidi Mohamed Ben Abdallah University, Fez, Morocco. It is supported by the University of Zinder (Niger) and the National Center for Scientific and Technical Research of Morocco (CNRST). The main objective is the computation of the first gravimetric geoid model and its applications in GNSS levelling in Niger. The authors would like to thank all data providers: Bureau Gravimétrique International (BGI) and ORSTOM (now IRD, Institut de Recherche pour le Développement) for terrestrial gravity data, the International Centre for Global Earth Models (ICGEM) for making GGM data freely accessible and the calculation service, and all institutions that made the Global Digital Elevation Models freely available to the public (NASA, USGS and CGIAR-CSI). The authors are also grateful for the comments and recommendations of the reviewers.

\section{Author contributions}

Ibrahim Yahaya Salissou conceived, designed, and performed the experiments; Ibrahim Yahaya Salissou and El Azzab Driss analyzed the data and wrote the paper.

\section{Disclosure statement}

The authors declare no conflict of interest. 


\section{References}

Barthelmes, F., \& Köhler, W. (2016). International Centre for Global Earth Models (ICGEM). Journal of Geodesy, the Geodesists Handbook, 90(10), 907-1205. Retrieved from http:// icgem.gfz-potsdam.de/ICGEM/

Bureau Gravimétrique International. (2015). Land gravity data. Retrieved from http://bgi.omp.obs-mip.fr/data-products/ Gravity-Databases/Land-Gravity-data

Drinkwater, M. R., Floberghagen, R., Haagmans, R., Muzi, D., \& Popescu, A. (2003). GOCE: ESA's first earth explorer core Mission. In G. Beutler, M. R. Drinkwater, R. Rummel, \& R. Von Steiger (Eds.), Earth gravity field from space from sensors to earth sciences (Vol. 17, pp. 419-432). Netherlands: Springer. https://doi.org/10.1007/978-94-017-1333-7_36

Forsberg, R. (1984). A study of terrain reduction, density anomalies and geophysical inversion methods in gravity field computation (Technical report No. 355). Department of Geodetic Science and Surveying, Ohio State University, Columbus.

Forsberg, R., \& Tscherning, C. C. (2008). An overview manual for the GRAVSOFT Geodetic Gravity Field Modelling Programs (2nd ed.). Department of Geodetic Science and Surveying, No. 341. The Ohio State University, Columbus, Ohio.

Förste, C., Bruinsma, S. L., Abrikosov, O., Lemoine, J. M., Marty, J. C., Flechtner, F., Balmino, G., Barthelmes, F., \& Biancale, R. (2014). EIGEN-6C4 The latest combined global gravity field model including GOCE data up to degree and order 2190 of GFZ Potsdam and GRGS Toulouse. GFZ Data Services. https://doi.org/10.5880/icgem.2015.1

Gilardoni, M., Reguzzoni, M., \& Sampietro, D. (2015). GECO: a global gravity model by locally combining GOCE data and EGM2008. Studia Geophysica et Geodaetica, 60(2), 228-247. https://doi.org/10.1007/s11200-015-1114-4

Greigert, J., \& Pougnet, R. (1965). Carte Géologique de la République du Niger. Bureau de recherches géologiques et minières France.

Grombein, T., Seitz, K., \& Heck, B. (2013). Optimized formulas for the gravitational field of a tesseroid. Journal of Geodesy, 87(7), 645-660. https://doi.org/10.1007/s00190-013-0636-1

Hammer, S. (1939). Terrain corrections for gravimeter stations. Geophysics, 4(3), 184-194. https://doi.org/10.1190/1.1440495

Hayford, J., \& Bowie, W. (1912). The effect of topography and isostatic compensation upon the intensity of gravity. Bulletin of the American Geographical Society, 44(6), 464-465. https://doi.org/10.2307/199909

Heiskanen, W. A., \& Moritz, H. (1967). Physical geodesy. San Francisco, London.

Hirt, C., Featherstone, W. E., \& Marti, U. (2010). Combining EGM2008 and SRTM/DTM2006.0 residual terrain model data to improve quasigeoid computations in mountainous areas devoid of gravity data. Journal of Geodesy, 84(9), 557567. https://doi.org/10.1007/s00190-010-0395-1

Hirt, C., Gruber, T., \& Featherstone, W. E. (2011). Evaluation of the first GOCE static gravity field models using terrestrial gravity, vertical deflections and EGM2008 quasigeoid heights. Journal of Geodesy, 85(10), 723-740. https://doi.org/10.1007/s00190-011-0482-y

Hwang, C., Wang, C. G., \& Hsiao, Y. S. (2003). Terrain correction computation using Gaussian quadrature. Computers \& Geosciences, 29(10), 1259-1268.

https://doi.org/10.1016/j.cageo.2003.08.003

Ibrahim Yahaya, S., \& El Azzab, D. (2018). Vertical accuracy assessment of global digital elevation models and validation of gravity database heights in Niger (Project).
Ibrahim Yahaya, S., El Brirchi, E. H., \& El Azzab, D. (2017a). Impact of datum transformation on local variations of geometric geoid in Niger. Geodesy and Cartography, 43(4), 147-157. https://doi.org/10.3846/20296991.2017.1412615

Ibrahim Yahaya, S., El Brirchi, E. H., \& El Azzab, D. (2017b). Mise en place d'une base de données géographique pour le calcul du géoïde gravimétrique au Niger. In Congrès International MORGEO2007 sur les Technologies Géospatiales: Applications et Perspectives, 16-17 Mai 2017. Casablanca, Maroc. Ismail, Z. (2016). Détermination de l'exactitude d'un géö̈de gravimétrique (Thèse de Doctorat en Géodésie). Université de Recherche Paris Sciences et Lettres, Ecole doctorale Astronomie et Astrophysique d'Ile de France, LAboratoire de REcherche en Géodésie, Paris.

Jarvis, A., Reuter, H. I., Nelson, A., \& Guevara, E. (2008). Holefilled seamless SRTM data V4 (Technical report). International Centre for Tropical Agriculture (CIAT). Retrieved from http://srtm.csi.cgiar.org

Kirby, J., \& Featherstone, W. (2002). High-resolution grids of gravimetric terrain correction and complete Bouguer corrections over Australia. Exploration Geophysics, 33(4), 161. https://doi.org/10.1071/EG02161

Kloch, G., \& Krynski, J. (2008, May). Towards optimisation of the determination of terrain corrections with the use of prism method. In The 7th International Conference "Environmental Engineering" (Vol. 3, pp. 1345-1353). Vilnius.

Nagy, D., Papp, G., \& Benedek, J. (2000). The gravitational potential and its derivatives for the prism. Journal of Geodesy, 74(7), 552-560. https://doi.org/10.1007/s001900000116

Pavlis, N. K., Factor, J., \& Holmes, S. (2007). Terrain-related gravimetric quantities computed for the next EGM. In 1st International Symposium of the International Gravity Field Service (IGFS) (Vol. 18, pp. 318-323). Harita Dergisi, Istanbul.

Pavlis, N. K., Holmes, S. A., Kenyon, S. C., \& Factor, J. K. (2012). The development and evaluation of the Earth Gravitational Model 2008 (EGM2008). Journal of Geophysical Research, 117(B4), B04406. https://doi.org/10.1029/2011JB008916

Rechenmann, J. (1966). Catalogue des stations gravimétriques réoccupables en Afrique occidentale. Mesures effectuées de 1953 à 1965. Cahier d'ORSTOM - Série Géophysique, no. 7.

Rechenmann, J. (1969). Cartes gravimétriques du Niger: note explicative $n^{\circ} 36$. Office de la Recherche Scientifique et Technique Outre-Mer(ORSTOM). Paris.

Seeber, G. (2003). Satellite Geodesy. New York (2nd ed.). Berlin, New York: Walter de Gruyter.

https://doi.org/10.1515/9783110200089

Seitz, K., \& Heck, B. (2001). Tesseroids for the calculation of topographic reductions. In Abstracts Vistas for Geodesy in the New Millenium. IAG.

Torge, W. (2001). Geodesy (3th ed.). Berlin, New York: Walter de Gruyter. https://doi.org/10.1515/9783110879957

Tziavos, I. N., \& Sideris, M. G. (2013). Topographic reductions in gravity and geoid modeling. In F. Sansò \& M. G. Sideris (Eds.), Geoid Determination (Vol. 110, pp. 337-400). Berlin, Heidelberg: Springer. https://doi.org/10.1007/978-3-540-74700-0

Varga, M., \& Bašić, T. (2015). Accuracy validation and comparison of global digital elevation models over Croatia. International Journal of Remote Sensing, 36(1), 170-189. https://doi.org/10.1080/01431161.2014.994720 